\title{
STRATEGIC SUCCESS IN THE INTERACTIVE RELATIONSHIP BETWEEN LOCAL POLITICS AND STRATEGIC SUPREMACY CASE STUDY IN DHI QAR GOVERNORATE
}

\author{
Haneen Qasim Hasan. Prof. Abdulrazzaq Ibraheem Al-Sheikli \\ University of Baghdad / College of Administration and Economics
}

DOI: $10.37648 /$ ijrssh.v10i02.042

Received: 15 ${ }^{\text {th }}$ April, 2020; Accepted: 05 ${ }^{\text {th }}$ May, 2020; Published: $15^{\text {th }}$ May, 2020

\section{ABSTRACT}

The aims of this study to test "the relationship between local politics and strategic Supremacy as independent variables and strategic success as a dependent variable. For this purpose, a number of hypotheses were formulated, the most important of which were finding a correlation and influence (local politics and its dimensions with strategic success) and (strategic Supremacy and its dimensions with strategic success).To achieve hypothesis tests, a case study was used and applied to the Department managers of Government of the province of Thi Qar. The number of the scope of the study is (75) responded, and the data was collected through the questionnaire, and personal interviews with a number of managers, heads of departments. A number of statistical methods have also been used to process data through a set of statistical programs (SPSS, Amos, PPR 2.16.3). As for the most prominent conclusions, they were represented: The existence of the strategic supremacy variable, clearly, but it is not used effectively in local politics to achieve strategic success. The research concluded with a number of recommendations, the most important of which were: Not use strategic supremacy positively for the Support of local politics, including Design, implementing and monitoring ignorance of them in how to use this supremacy to achieve strategic success and public serve.

Keywords ; local politics, strategic Supremacy, strategic success

\section{RESEARCH PROBLEM}

The lack of clarification about the relationship among the variables studied (local policy, strategic supremacy, strategic success) The resulting poor output and duplication of tasks give the researcher an opportunity to put more work into clarifying this relationship and addressing the theoretical and practical intellectual debate. As the latter poses the greatest research question, as these proposals have been a question in developed countries that are not considered an emergency, so how in developing countries, especially
Iraq, and under modernity. The main research problem is if there is an effective relationship of strategic supremacy to local politics to achieve strategic success.

\section{RESEARCH OBJECTIVES}

1. To provide an in-depth theoretical structure for local politics and orientation towards strategic progress and supremacy political in the research scope.

2. To Understanding the extent of Thi Qar Governorate readiness and its capacity to enable the dimensions of strategic supremacy in the service sector to help 
improve the dimensions of strategic performance political in the research scope.

3. Comes with a number of conclusions and recommendations and submitting a proposed model for local government in Thi Qar Governorate that contributes to strategic success in the light of the collaborative relationship between local policy and strategic supremacy.

\section{THE HYPOTHESIS OF THE RESEARCH}

As a result of what was presented in the research problem and its importance and basic goals, a hypothetical structure was formulated and designed in Figure 1, which expresses the nature and type of basic and subsidiary relationships between research variables.

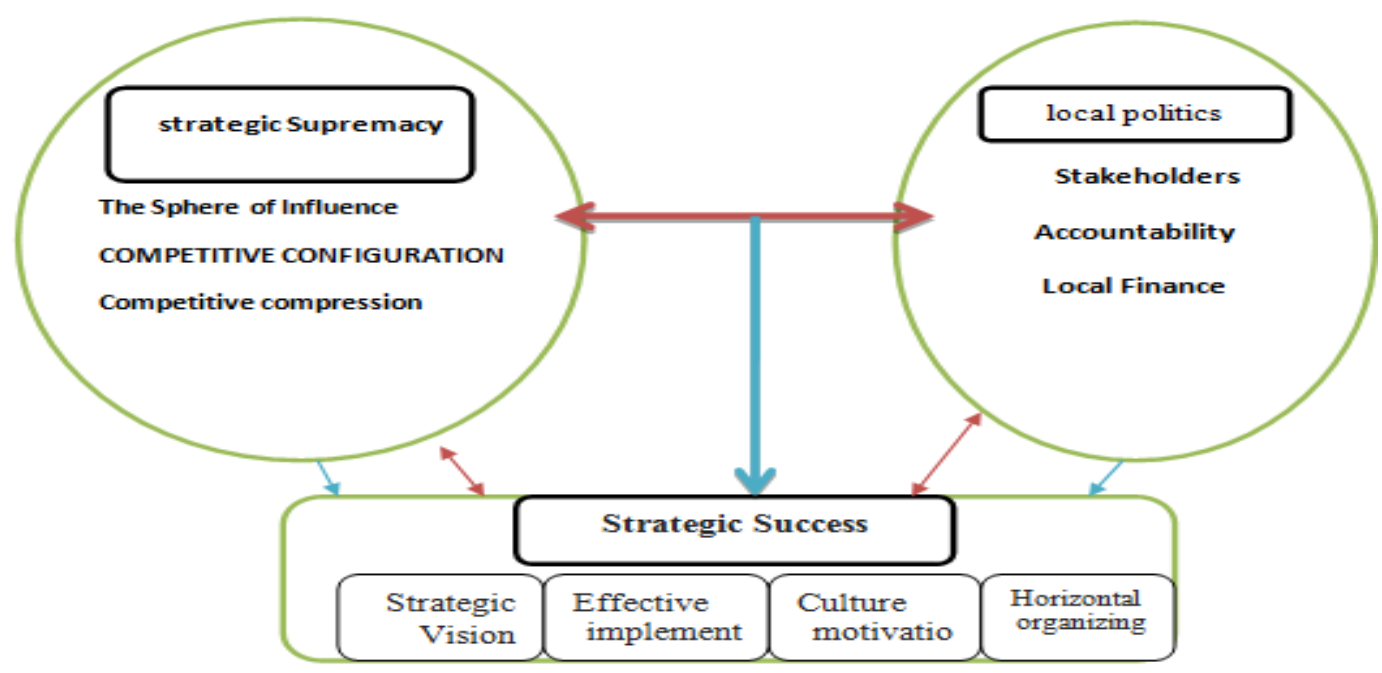

\section{Figure 1: Research Model}

\section{IMPORTANT OF THE STUDY}

1. Review practical perspectives that mimic managerial thought in two key areas of management as a starting point for strategic progress, local policy and strategic supremacy, especially the area of strategic governance, to gain a common understanding and interpretation of principles and goals.

2. The study focused on the sector, which is considered to be the primary source for the advancement of the administrative reality of the country, in particular with regard to local authorities in Iraq.

3. This research is a guide for the directors of the departments of Thi Qar Governorate to deal with the strategic supremacy that belongs to these local administrations, and whose results are supposed to reflect positively on the strategic success.

\section{STRATEGIC SUCCESS}

Success is a language that is derived from the word "success", and it is an expression of the thing that a person obtains after fatigue and great effort. It has been said that success succeeded, success succeeded (A1Fayyad, 2011). As achieving the goal and winning the required thing, which is setting realistic and concrete goals correctly, and defines it (Natalia, 2016: 6) The method followed by the organization characterized by innovative and renewable ideas aimed at adaptation, survival and growth in light of competitive conflict, The researchers believe that strategic success includes formulating a concise and clear strategic vision with a commitment to a successful motivational culture to achieve the goals of the organization efficiently and effectively and to move away from the routine and give way to creative and thinking cadres to ensure the effective implementation of those goals. 


\section{Horizontal organization:}

Successful organizations perform their work through a decentralized system, and their branches and departments are able to make sound and sound decisions as a result of delegation and authority. As for unsuccessful organizations, they operate under strict centralization of powers and responsibilities and concentrate them in senior management only, which leads to hampering their capabilities in Competition with other organizations (Drucker: 1995: 25). Finally, we conclude that horizontal organization is one of the practices implemented by the applied units of administrative decentralization, and this last leads to giving higher departments greater powers to conduct their business and empower their workers without killing creativity in the vicious bureaucracy, as horizontal organization has become a necessity required by today's work environment and the breadth of work Organizations and the difficulty of restricting business centrally to one hand only.

\section{Motivational culture:}

Successful and superior organizations possess a stimulating and positive culture of work, while other organizations live under the shadow of a routine culture that is constantly constraining their activities (Ali, 2019), and the role of motivational culture is concentrated in that it can be carried out at all levels and activities within the organization. It leads to the success of the organization if it actively contributes to providing an appropriate climate that encourages improving and developing performance and enhancing creativity trends. It can also result in the organization's failure if it results in obstacles that prevent achieving the efficiency and effectiveness of the system (Al-Hussein, 2018: 226). The culture that an organization motivates employees influences Working procedures and thus on organizational performance and this is what a group of research has focused on in an attempt to discover the relationship between culture and performance.

\section{Effective implementation:}

The process of formulating the strategy is a dynamic and complex task, as working to implement it and putting it into actual implementation successfully is actually a more difficult and complex challenge. The failure of management to implement the strategy is not only limited to this stage, but also includes the failure of strategic management as a whole, and whatever it is. The organization is successful in formulating its mission and defining its strategic goals all become meaningless if they are not placed in an appropriate organizational context and are subsequently translated into appropriate implementation steps (Yassin, 2010: 159).

Finally, it can be said that the boundary between failure and success in public organizations is effective implementation, which emphasizes the accuracy of formulation and the employment of the strategic vision and thus knowledge of the obstacles to implementation and the pursuit of avoiding them in the future.

\section{Strategic vision:}

A vision is a slogan consisting of one sentence that explains the general goal that you want to reach after a period of time, for example five years, by identifying problems, discussing them, and finding the desired goals for the organization (Wolfe et al, 2017: 5).

Finally, it can be said that the strategic vision is one of the complex processes that should not be placed in the hands of unqualified people who do not have a degree of creativity and strategic thinking, as the organization sets a single vision that represents the lofty goal that the organization wants to achieve by setting a few words and expressing those goals .

\section{LOCAL POLITICS}

These are policies that are limited to one of the parts or one of the governorates that are characterized by a specific privacy such as poverty or education, national holidays and holidays, trying to differentiate between them and the general policies that are comprehensive for all geographical regions of the state (Al-Kubaisi, 2008). It can be said that the local policy is nothing but a set of plans and programs that are prepared by elected local bodies and it is an ongoing uninterrupted process that includes legislation, implementation and oversight and then the evaluation later on the policies drawn by the local administration of the relevant governorate and the mechanism for its implementation by government departments and agencies Belonging to that province, while the process of drawing up, implementing, and monitoring local policy is a complex process that includes a set of different stages from one researcher to another, as the researcher summarized a group of researchers 'views to determine the basic steps for 
drawing up local policy, as you can We mention these stages in order in the following points Defining the problem, Stimulating the government's interest in the problem and including it in its agenda, . Drawing up general policy proposals to confront and solve the problem, Adoption of the policy and Funding policy (Hassan, 2016).

\section{Local policy variables as}

\section{Stakeholders:}

Stakeholders represent organized groups of people who have common values, goals, and interests and aim to influence decision makers in all state organizations, as well as called lobbying groups, and not all stakeholders act in the same way to influence local policy (Yaghi, 298: 2012).

\section{Accountability:}

The definitions of accountability are numerous and varied in a clear way, but they revolve around the idea of having two sides, the first is to allocate, define and enable validity, and the second is accepted with the commitment to the right of accounting and writing reports for the first party (ECSAFA, 2002: 9), as accountability is one of the concepts widely used It is broad in the field of public administration, due to the fact that it represents a tool to control the performance of workers in the organization as it is a primary means to combat administrative corruption, which has become a global phenomenon with many negative effects, at the same time it plays an important role in achieving effectiveness for any organization, in other words that accountability It is the first and development episodes Administrative reform (Abdul-Jabbar 2012: 102).

\section{Local financing:}

Public policy financing depends on the local level on what is allocated in the governorate's annual budget from the general federal budget and local revenue, and assigns special committees to present projects next year in the middle of the current year and submit projects that need funding to be studied in general by a central committee The Reconstruction Office, the Office of Strategic Planning, and the Economic Committee include to conduct a joint study. This committee sets an annual plan taking into consideration the ongoing projects to allocate funds from it to the budget and on the basis allocated to the province from the development projects of the regions (Jihad, 2015)

\section{STRATEGIC SUPREMACY}

supremacy is defined in a language: that the word pronounced the Lord and the owner of the king or the virtuous person or the generous person, and he continued from the verb) prevailed. Prevail (he is the master (Abdel Qader, 2019: 80)

As for idiom: it is the supreme authority that does not know in regulating its relationship with another supreme authority (Saad, 2003: 180)

While (D'Avenie, 2004: 37) defined strategic supremacy as building new advantages to replace the old in order to move competitors and push them to continue competition and expand their influence by providing value to the recipient of the service or commodity in directions that do not conflict with their ambitions so that they can Shifting their resources against other competitors.

Variables of strategic supremacy AS

\section{The Sphere of Influence:}

the area of influence is the heart of strategic supremacy and is the geographical portfolio of public organizations services and focuses on the field that belongs to them and the main area that it owns which is the local community the site of research and this can be explained by knowing the local environment expectations and competitive pressures when it comes to quality and performance and the combination of these two standards, Therefore, the sphere of influence is not a set of core capabilities and this is what the basic work environment is based on, but it is considered the beginning and connects with everything that surrounds its work environment through joint capabilities and economies of scale, scope and field of Organization (D'Aveni, 1999: 30)

Therefore, competing organizations in a multicompetitive environment find balance through the sphere of influence, but when the information is insufficient, it may give the organization an incentive to influence the behavior of opponents to disclose information, and the organization may use the allocation of resources to rebuild its sphere of influence in the competitive markets, and it can improve the 
allocation of resources The sphere of influence reduces overall and destructive competition.

\section{COMPETITIVE CONFIGURATION :}

How do superpowers achieve supremacy? The key is mastering the art of competitive training - the ability to create a structure that includes alliances, goals, and areas of great power that reflects the organization's world view regarding the competitive space, and the organization's vision is its vision of competitive training, including the way you want to define the total competitive area, and when addressing The organization has looked at the world, many alternative competitive configurations may be equally desirable, in which case you have to consider the available capabilities and you must choose one alternative and follow it with all strength in your field, otherwise you will end up with a mixed formation that does not correspond to Any of the visions of the alternative organization for the region. (D'Aveni, 2001)

\section{Competitive compression:}

D'Aveni is similar to competitive pressure in a balloon when the pressure increases. The balloon expands but cannot continue indefinitely. Often organizations feel competitive pressure in highly competitive areas, and pressure may be from one competitor or may be From several competitors with intent or unintentionally, they may agree to work together, or this pressure may be as much as the strategic field and the natural growth of the development of the sphere of influence (D'Aveni, 1999).

\section{THE PRACTICAL FRAMEWORK OF RESEARCH}

First: Results of the test of normal distribution of data:

Table 2 shows the results of the normal distribution test using the Kolmogorov-Smirnov test, which is known in this field at the level of the variable and the studied dimensions that are included in the hypothesis test models. Table ( ) shows that the value of the significance of the variable and the dimensions of the research is Greater than significance (0.05)This indicates that the data follows the natural distribution of both (strategic flexibility, interactive flexibility and proactive flexibility)If the results of the test are not significant, accept the hypothesis of natural distribution and reject the alternative hypothesis and vice versa (Pallant, 2001: 58)

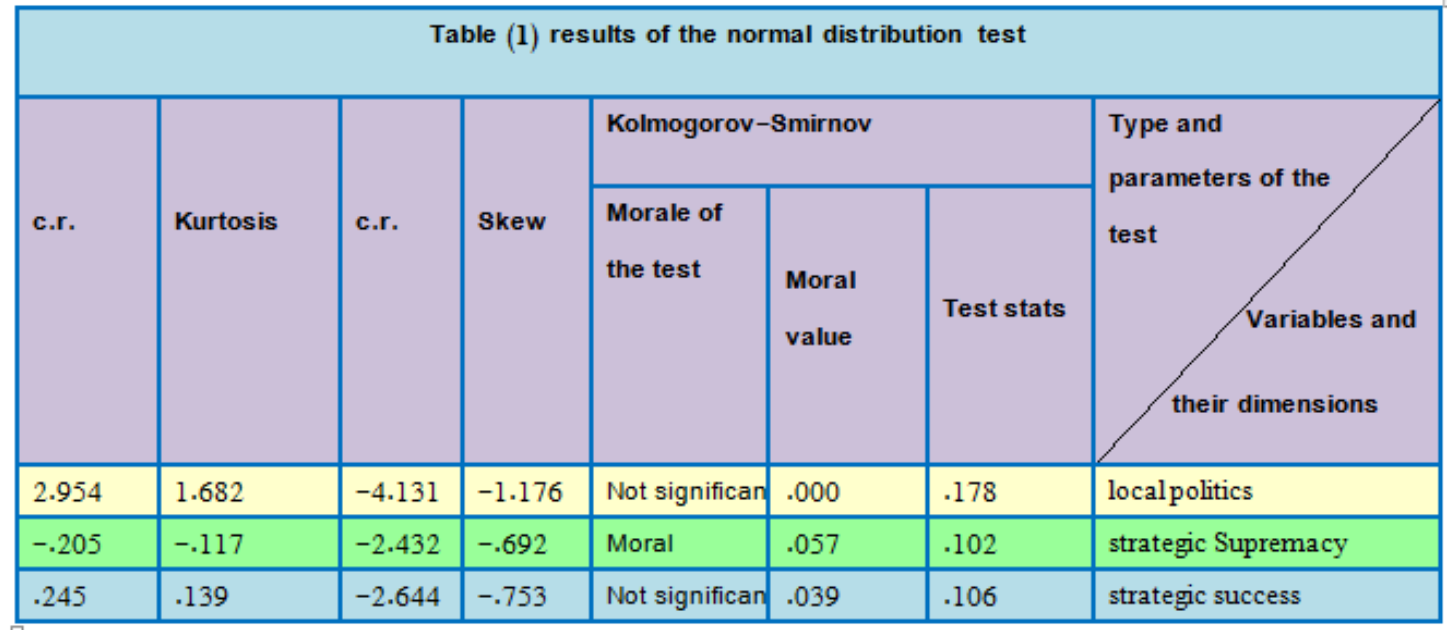

Second: truth the measurement tool search

The concept of the instrument's reliability refers to the ability to accurately and reliably measure the construction to be measured, ie, the extent to which the measuring instrument represents the characteristics that exist in the phenomenon under investigation. This side has three axes: Split-half, the consistency between components of the scale (alphacronbach), the construction truth of a test for the measuring instrument, the empirical analysis.

\section{1- The consistency between components of the scale (Alpha Cronbach)}

This test is used to measure the degree of consistency of the answers of the interrogator to all the questions on the scale. To the extent that each question measures the same concept, these questions are interrelated, and the most common test for measuring the degree of The consistency between components of the scale is the scale called the Cronbach Alpha 
coefficient. By using Cronbach Alpha, Table 3 shows the consistency between the components of the scale at the level of the dimensions and the strategic elasticity, all of which have exceeded the Cronbach Alpha correlation coefficients to the acceptable minimum (0.70) The consistency between the components of the scale and the stability of the required in the event of repeated testing.

\begin{tabular}{|l|l|l|}
\hline \multicolumn{2}{|c|}{ Table (2) Results of the internal consistency test for the scale } \\
\hline Honesty & $\begin{array}{l}\text { Alpha Cronbach } \\
\text { dimensional } \\
\text { coefficient }\end{array}$ & the scale \\
\hline 0.977 & 0.955 & local politics \\
\hline 0.977 & 0.954 & strategic Supremacy \\
\hline 0.977 & 0.955 & $\begin{array}{l}\text { All paragraphs of } \\
\text { the questionnaire }\end{array}$ \\
\hline 0.980 & 0.961 & \multicolumn{2}{|c|}{} \\
\hline
\end{tabular}

2- Internal consistency of the Split-half Reliability Tests

The internal consistency of the standards is an indication of the homogeneity of the components of the measure that measures a particular concept or theory. That is, questions should be interrelated with each other as a group that measures a particular concept. Meaning that the sample understands the total meaning of the scale and each of the questions that comprise it. (Sikaran, 2009: 294). It is possible to identify the internal consistency of the scale by identifying the correlation between the constituent questions or by the confidence tests in the two halves of the measure (Split-half Reliablitiy Tests), which will be adopted by the researcher, The correlation between the scores of the individual questions and the scores of the marital questions in the questionnaire and the correlation coefficient is corrected by the Spearman Brown equation. If the coefficient of constancy (0.67) according to the equation is sufficient for the research on which the questionnaire is based, The questionnaire reached (0.914).

\begin{tabular}{|c|c|c|c|}
\hline \multicolumn{4}{|c|}{ Half - way method (Split -Half ) } \\
\hline \multirow{5}{*}{$\begin{array}{l}\text { Cronbach's } \\
\text { Alpha }\end{array}$} & \multirow[t]{2}{*}{ Part 1} & Value & .900 \\
\hline & & $\mathbf{N}$ of Items & $26^{\mathrm{a}}$ \\
\hline & \multirow[t]{2}{*}{ Part 2} & Value & .934 \\
\hline & & $\mathrm{N}$ of Items & $26^{b}$ \\
\hline & \multicolumn{2}{|c|}{ Total N of Items } & 52 \\
\hline \multicolumn{3}{|c|}{ Correlation Between Forms } & .841 \\
\hline \multirow{2}{*}{$\begin{array}{l}\text { Spearman- } \\
\text { Brown } \\
\text { Coefficient }\end{array}$} & \multicolumn{2}{|c|}{ Equal Length } & .914 \\
\hline & \multicolumn{2}{|c|}{ Unequal Length } & .914 \\
\hline \multicolumn{3}{|c|}{ Guttman Split-Half Coefficient } & .908 \\
\hline
\end{tabular}




\section{Third: To present and analyze the results according to the sample answers}

And to ensure the presence of the effect of two variables that were tested using multiple linear regression, as the clear results in Table (61) showed the following:

1- Through table (61) it is clear that the value of the correlation coefficient between local policy and strategic supremacy has reached $\left(0.843^{* *}\right)$ and with a level of significance $(0.000)$ which is smaller than the level of significance (0.05) and this indicates that there is a correlation between policy Local and strategic supremacy.

\begin{tabular}{|c|c|c|c|}
\hline \multicolumn{4}{|c|}{ Table (3) The correlation between local politics and Strategic Supremacy } \\
\hline $\begin{array}{l}\text { strategic } \\
\text { Supremacy }\end{array}$ & local politics & Link and levelSig & \\
\hline $0.843 * *$ & \multirow{2}{*}{1} & correlation & \multirow{2}{*}{ local politics } \\
\hline .0000 & & $\mathrm{Sig}$ & \\
\hline \multirow{2}{*}{1} & $* * 0.843$ & correlation & \multirow{2}{*}{$\begin{array}{l}\text { strategic } \\
\text { Supremacy }\end{array}$} \\
\hline & .0000 & Sig & \\
\hline
\end{tabular}

2- The calculated value of (F) of the hypothesis (there is an effect of both local politics and strategic supremacy on strategic success) $(87,443)$. It is greater than the tabular value $(F)$ of $(3.83)$ at the level of significance $(0.05)$ and, accordingly, we reject the null hypothesis and accept the alternative hypothesis which states (There is a significant effect between local policy and strategic supremacy together in strategic success (at the level of significance) $5 \%$ (i.e. with a confidence degree $(95 \%)$ ), and through the value of the identification parameter $\left({ }^{2} \mathrm{R}\right)$ of $(0.711)$, it becomes clear that local politics and strategic supremacy explain $(71 \%)$ of the variables that occur in strategic success, while the remaining ratio of (29) \%) Refer to other variables not included in the search form. It is clear from the value of the marginal slope coefficient $(1 \beta)$ of $(0.416)$ that an increase in domestic policy by one unit will lead to an increase in strategic success by (42\%), and it is clear through the value of the marginal slope coefficient $(1 \beta)$ of $(0.308)$ that an increase Strategic supremacy by one unit will increase strategic success by $(31 \%)$.

\begin{tabular}{|c|c|c|c|c|c|c|c|c|}
\hline Searc & iables & & Estimate & $\begin{array}{l}\mathrm{T} \\
\text { Calculate }\end{array}$ & S.E. & $\begin{array}{l}\mathrm{F} \\
\text { Calculate }\end{array}$ & $\mathrm{R}^{2}$ & $\mathrm{P}$ \\
\hline$\frac{1}{2}$ & $\mathrm{X} 1$ & $\begin{array}{l}\text { local } \\
\text { politics }\end{array}$ & 0.416 & 4.458 & 0.093 & & & \\
\hline 苞 & $\mathrm{X} 2$ & $\begin{array}{l}\text { strategic } \\
\text { Supremac } \\
\mathbf{y}\end{array}$ & 0.308 & 3.735 & 0.082 & סרוטר & & 0.000 \\
\hline
\end{tabular}


the multiple impact of local politics and strategic supremacy on strategic success

And now we are testing a hypothesis (there is a significant effect of the interactive relationship between local politics and strategic supremacy in strategic success) and the results of this hypothesis have been extracted through the program (PPR2.16) based on the model (Hayes, 2013: 81) illustrated by Table (63) and Figure (40) include the following:

1- The calculated value of $(\mathrm{F})$ for the interactive relationship between local politics and strategic supremacy in strategic success was (0.324). It is smaller than the tabular value (F) of (3.83) at the level of significance (0.05) and, accordingly, we reject the alternative hypothesis and accept the null hypothesis which states (No effect is significant Significant indication of the interaction relationship between local politics and strategic supremacy in strategic success) at the level of significance (5\%), with a degree of confidence $(95 \%)$.

2- And through the value of the determining factor $\left({ }^{2} \mathrm{R}\right)$ of $(0.0013)$, it is clear that the amount of increase or change occurring in the interactive relationship between local politics and strategic supremacy was (0.0013), which is very little or almost non-existent, as this value indicates that there is no Any change has occurred for the interaction between local politics and strategic supremacy.

Thus, as a result of the foregoing, the following is evident:

The absence of an interactive relationship between local politics and strategic supremacy in strategic success, meaning that local politics and strategic supremacy have an independent characteristic of influencing strategic success, knowing that they have a high rate of influence and effective and effective on strategic success as they are independent, but the characteristic of interaction Not fulfilled. In other words, there was no interaction between local politics and strategic supremacy together to show us an interactive variable that affects strategic success. The researcher believes that the reason for this is that there is a large gap between local policy and strategic supremacy and not interacting with them both within the Diwan Qar governorate office, as the local policy and strategic supremacy are not fixed and are constantly changing. The electoral cycle begins with a new policy, and therefore at the same time, this policy does not go with the strategic supremacy of the governorate, which was supposed to be characterized by stability and continuity, and therefore, instability and communication between local policy and strategic supremacy has been approved. Are the recipe in order to influence the interaction in a more strategic success.

\begin{tabular}{|c|c|c|c|c|c|c|c|c|c|}
\hline \multicolumn{10}{|c|}{$\begin{array}{l}\text { Table (5) The relationship of local politics and strategic Supremacy and its impact on strategic } \\
\text { success }\end{array}$} \\
\hline \multicolumn{3}{|c|}{ Search variables } & Estimate & $\begin{array}{l}\text { T } \\
\text { Calcul }\end{array}$ & S.E. & $\begin{array}{l}\text { F } \\
\text { Calcula }\end{array}$ & $\mathbf{R}^{2}$ & $\mathbf{P}$ & $\begin{array}{l}\text { Se } \\
\text { arc } \\
\text { h } \\
\text { var }\end{array}$ \\
\hline \multirow{3}{*}{ 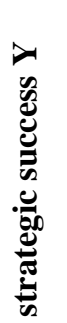 } & $\mathrm{X1}$ & local politics & .485 & 3.161 & .153 & .002 & \multirow[b]{2}{*}{57.848} & \multirow[b]{2}{*}{0.713} & \multirow{2}{*}{.00} \\
\hline & $\mathrm{X} 2$ & $\begin{array}{l}\text { strategic } \\
\text { Supremacy }\end{array}$ & .405 & 2.122 & .191 & .037 & & & \\
\hline & $\mathrm{X} 1 * \mathrm{X} 2$ & $\begin{array}{l}\text { Interactive } \\
\text { relationship }\end{array}$ & 0.030- & $0.569-$ & .053 & .571 & 0.324 & $\begin{array}{l}0.001 \\
3\end{array}$ & $\begin{array}{ll}0.5 \\
71\end{array}$ \\
\hline
\end{tabular}




\section{CONCLUSIONS AND RECOMMENDATIONS}

\section{First: Conclusions}

1. The results indicate that the Court of Dhi Qar Governorate does not have a significant characteristic of its own culture, as we find its culture indiscriminate, unidentified or directional.

2. The results of the research focused on the financing process, its importance in governing matters, and the extent to which financial conservative matters are hindered when the annual budget project announcement is delayed, which has become a matter of routine during the previous 17 years.

3. The presence of the strategic supremacy variable clearly, but it is not used effectively in local politics to achieve strategic success.

\section{Second: Recommendations}

1. The need to support the motivational culture of workers and extrapolate from the reality of the province, that is, the methods that are most influential in improving the behavior of workers within the bureau, in order to sharpen the concern to complete the work with all motivation and vitality.

2. Training the cadres and making them constantly informed of what is happening in the local competitive environment (between governorates) and the global environment and not to isolate them within government departments and confine them to office work only in order to work according to the requirements of the modern environment

3. With the existence of strategic supremacy with the local government of Dhi Qar Governorate, but it does not employ it positively in favor of the local policy, from drawing, implementing and monitoring ignorant of it in how to use this supremacy to achieve the public interest, so the researcher recommends giving way to certificates holders with experience in the field of administration and law And the other vital magazines that affect the work of the province and provide them with the people of experience who worked a long time in the province, forming a solid team in order to discuss the methods and methods that enhance the utilization of the supremacy enjoyed by local government agencies and departments to achieve strategic success.

\section{REFERENCES}

1. Abdel Qader, Muhannad Zia, (2019), Obstacles to Achieving Popular supremacy, and its Implications, Journal of Legal and Politics, Vol. 8, No. 1.

2. Abdul-Jabbar, Mona Haider, (2012), The Role of Governance in Building Effective Organizations: An Exploratory Analytical Study / The Ministry of Higher Education and Scientific Research in Iraq, a thesis submitted to the Board of the College of Administration and Economics / University of Baghdad as part of the requirements for obtaining a $\mathrm{PhD}$ degree in Philosophy in Public Administration Sciences.

3. Al-Bashqali, Mahmoud Muhammad Amin and Sultan, Hikmat Rashid, (2019), the role of strategic cooperation in achieving strategic supremacy, an exploratory study of the views of administrative leaders from private universities in the Kurdistan Region of Iraq, the scientific journal of the University of CeyhanSulaymaniyah, Vol. 3, p. 1, 293_329.

4. Al-Fayadh, Majeed Hameed Taher, (2011) "The Impact of Human Resources Management Strategies in Achieving Strategic Success / Field Study at the Ministry of Oil," a letter presented to the Council of the College of Administration and Economics at the University of Baghdad to obtain a Master of Science degree in Public Administration.

5. Al-Hussein, Hoda Salem, (2018), the use of strategic analysis of operational income in assessing strategic success, a case study at the General Company for Northern Cement in Mosul, Tikrit University - College of Administration and Economics, Tikrit Journal of Administrative and Economic Sciences, Volume 2, No. 22, Part 1.

6. Al-Kubaisi, Amer Khudair, (2008), Public Policy: An Introduction to Developing Governmental Performance, Publications of the Arab Organization for Administrative Development, Saudi Arabia, Riyadh. 
7. D , Aveni ,Richard A.,( 2001), "Strategic Supremacy How Industry Leaders Create Growth" , Wealth and Power through Spheres of influence, with Robert Gunther and Joni Cole , 1230 Avenue of the Americas new york, 10029 ,Copyright .

8. D,Aveni Richard A.,( 1999), "Strategic supremacy through Disruption and Dominance" , MIT Massachusetts, Institute of technology management Review, Vol.40, No.3.

9. D,Aveni Richard A.,( 2004), "Corporate spheres of Influence" , mitsioan management Review ,Vol.45,No.4 , P: 34-46

10. Drucker, Peter,(1995)," The Discipline of Innovation".

11. ECSAFA, (Eastern, Central \& South Africa Federation of Accountants), (2002), Governance in The Public Sector, Nairobi Kenya.

12. Hassan, Hanin Qasim, (2016), the effect of cultural intelligence on local policy-making in Dhi Qar Governorate Council ((exploratory research)), a letter submitted to the Council of the College of Administration and Economics / University of Baghdad, which is part of the requirements for obtaining a master's degree in public administration sciences.

13. Jihad, All Fakhr Falih, (2015), Making Internal Public Policies in Iraq: The Role of Local Government, Master Thesis, University of Baghdad, Political Science.

14. Natalia A. Zaitseva, Irina V. Goncharova, Marina E. Androsenko ,(2016)" Necessity of Changes in the System of Hospitality Industry and Tourism Training in Terms of Import Substitution "nternational Journal of Economics and Financial Issues, 6(1).

15. Pallant, Julie,(2011,(SPSS Survival Manual. A Step by step guide to data analysis using SPSS).4th ed, Printed in China at Everbest Printing CO. Australia.

16. Saad, Hadi, (2003), General International Dictionary _ Dar Al-Kutub Al-Alami - Beirut, 2nd edition.

17. Strikwerda, J,\& Rijnders,D,( 2005)," possible End Games in the European postal Market " ,cui Bone ? "in M.A. Crew ,\& P.R kleindorfer (Eds) Regulatory and Economic changes in the postal and Delivery sector . Amsterdam : Kluwer Academic publishers .

18. Wolfe Benjamin, Dobres Jonathan, Rosenholtz Ruth, Reimer Bryan,(2017 ) "More than the Useful Field Considering peripheral vision in driving” ‘journal .

19. Yaghi, Abdel-Fattah (2012), "The Government and Public Administration in the United States of America", 1st edition, (Amman: Dar Al-Hamid for Publishing and Distribution.(

20. Yassin, Saad Ghaleb (2010), "Strategic Management", second edition, Dar Al-Yazouri Scientific Publishing and Distribution, Amman. 